\title{
Sobre el sentido de la ética y el sentido del saber (Una aproximación a Levinas)
}

\author{
Belén Altuna \\ Universidad del País Vasco / EHU
}

\begin{abstract}
RESUMEN. Según Emmanuel Levinas, el sentido de la ética consistiría en una orientación pre-ontológica que hace que, en lugar de meros seres que están-conlos-otros, seamos seres que son-para-losotros, de modo que en la proximidad del cara-a-cara, el rostro del otro despierta en nosotros una responsabilidad para con él (y para con todos los otros que aparecen ya en él). Sin embargo, para cumplir con la llamada del rostro a menudo es necesaria alguna forma de mediación (de pensamiento, cálculo, generalización, despersonalización), alguna forma de "saber" que supone distancia y corre, por tanto, el permanente peligro de olvidar su sentido. De ahí las aporías y las dificultades inherentes a la proximidad sobre las que reflexiona la segunda parte de este artículo.
\end{abstract}

Palabras clave: Levinas, rostro, ética, ser-para-el-otro, responsabilidad, proximidad, justicia

Nació hace cien años, murió hace diez, y los textos de Levinas aparecen todavía como un vasto territorio en penumbra, un laberinto de proposiciones que crea una sensación de vértigo al lector primerizo. Al principio uno se pregunta por qué no puede expresar todo eso con un lenguaje conceptual más asequible, con una sintaxis menos oscura. Después, en el momento feliz en que lo oscuro comienza a devenir transparente, el lector no puede
AbStract. According to Emmanuel Levinas, the meaning of ethics lies on a pre-ontological orientation that helps us become a being for-the-other, instead of just a being with-the-other. In the proximity of a face-to-face encounter, the face of the other awakens in us a responsibility towards him or her, and also towards all those who already appear in him or her. However, in order to comply with the call of the other, some kind of mediation is often needed, some kind of "knowing" (thought, calculus, generalization, depersonalization) that entails some distance and therefore a risk of forgetting its meaning. As a result, some aporias and difficulties are inherent to proximity-those will be the subject matter of the second part of this paper.

Key words: Levinas, face, ethics, beingfor-the-other, responsability, proximity, justice.

sino reconocer que ningún concepto es utilizado de manera gratuita, que ese arduo lenguaje era seguramente necesario para sacarnos de nuestra tierra filosófica acostumbrada y llevarnos a otra, para descolocarnos y sembrarnos de dudas.

"Mi tarea no consiste en construir la ética; intento tan sólo buscar su sentido", afirma Levinas (EI:84). Y añade que lo que pretende la ética, tal como él la entiende, es "acceder a otro proyecto de 
inteligibilidad y a otra forma de amar la sabiduría" (EN, 9). Buscar el sentido de la ética. Cierto, toda su filosofía puede entenderse como una explicación en círculos de ese sentido, como la construcción linguística de una densa atmósfera en la que ese sentido toma una forma contundente. Pero no es únicamente el sentido de la ética lo que proporciona la teoría levinasiana, sino algo todavía más tremendo: el sentido del saber, el sentido de la racionalidad, el sentido de todo conocimiento y de toda filosofía ("otra forma de amar la sabiduría", es decir: otra filo-sofía); el sentido del ser, en definitiva.

Tal vez podríamos denominar "metafísica de la ética" o "ética metafísica" a lo que Levinas hace, y por tanto es importante señalar que él no se dedica a derivar de ahí ninguna ética normativa (lo que no quiere decir que otros no puedan hacerlo, claro está). No se trata, pues, de una ética deontológica y mucho menos de una eudaimonística. De hecho, utiliza pocas veces el término "deber" y más rara vez aún "felicidad". Tampoco habla nunca de "virtudes". No se trata de una ética de la autonomía, ni la libertad es lo primero ni lo principal. Tampoco se trata de una ética de la autenticidad, no hay nada remotamente parecido a un "sé tú mismo" o a un llamamiento al autoconocimiento o a una ética de la autorrealización. No hay espejos en Levinas. Ni siquiera los otros ejercen como espejos: no son "otros yos". Salvo cuando se le insta o en algún breve artículo, no habla de "derechos" y tampoco utiliza apenas "dignidad" o "respeto". La "racionalidad" no es exactamente el quid de la cuestión. Tampoco se basa en nociones como "comunicación" o "diálogo", pues tiende a apartar los términos que impliquen reciprocidad. Por eso mismo apenas hay "tú (s)" en sus textos, sino, siempre, "el otro".
¿Qué términos son, entonces, los que ha escogido principalmente para describir ese sentido de la ética? Para empezar, por supuesto: el otro, el tercero, el prójimo. Y bondad, responsabilidad, justicia, santidad. Y, por primera vez en la historia de la filosofía, y como concepto central: el rostro. El rostro del otro, de los otros, como fuente heterónoma de moralidad. Levinas reconstruye así el sentido de la ética a partir de la relación con el otro, a la que considera primaria u originaria respecto al principio de supervivencia o de autonomía individual. Ello supone criticar frontalmente el modelo de razón práctica desarrollado en el mundo moderno, ese imperativo que brota del deseo de sobrevivir o de perseverar en el ser propio, que en Hobbes se constituye en la raíz del poder político y en Spinoza, como conatus, en el principio de la motivación ética. Levinas explora, así, una forma de concebir la subjetividad y la alteridad completamente extraña a esa larga tradición del conatus.

El sentido puede entenderse como "razón de ser, finalidad", como "significado" y también como "orientación". Pues bien, ahí radica el centro del planteamiento levinasiano: los seres humanos tendrían un sentido previo a la ontología, anterior a la organización del ser, al momento de la racionalización y del conocimiento. Un sentido, entendido como orientación, que les hace no meramente seres sociales, seres que-están-CON-losotros, sino seres que-son-PARA-los-otros; una orientación pre-originaria (pre-ontológica, dirá Levinas, es decir, "de otro modo que ser") que les impulsa a salir de su propia subjetividad hacia el Otro.

En Totalidad e Infinito (1961), Levinas expone las líneas maestras de esta otra forma de conocimiento que no cesará de desarrollar hasta su muerte en 1995. Es la obra en la que ataca más sistemáticamente los presupuestos ontológicos de la 
filosofía occidental y que abre a esa distinta forma de "amar la sabiduría". A pesar de que hay matices importantes entre ésta y sus obras posteriores, es innegable la coherencia -y la consistencia- del conjunto de su obra, por lo que citaré indistintamente sus diferentes libros con el fin de ofrecer una visión general de lo que son, a mi juicio, las claves de su pensamiento ético.

\section{La responsabilidad que viene del rostro del otro}

\section{El Infinito del rostro frente a la Totalidad}

La noción de rostro es central en Levinas porque "significa la anterioridad filosófica del ente sobre el ser, una exterioridad que no recurre al poder ni a la posesión" (TI, 75). Y eso es precisamente lo que el grueso de esa tradición filosófica habría hecho: buscar el poder y la posesión. ¿Cómo? Funcionando como un inmenso aparato de tematización, de despersonalización, de tipologización. Un aparato que subsume toda diferencia en lo igual, lo Otro en lo Mismo, haciéndolo así manipulable, comprensible y comprehensible, objeto de poder. En general, la filosofía habría buscado la unidad, la identidad (la identificación); en una palabra: la Totalidad. Y, poniendo el ser por encima de los entes -los seres individuales de carne y hueso: los rostros-, habría entronizado la ontología como filosofía primera.

"La filosofía occidental ha sido muy a menudo una ontología: una reducción de lo Otro a lo Mismo, por mediación de un término medio y neutro que asegura la inteligencia del ser. Esta primacía del Mismo fue la lección de Sócrates. No recibir nada del Otro sino lo que está en mí, como si desde toda la eternidad yo tuviera lo que me viene de fuera. No recibir nada o ser libre... La neutralización del Otro, que llega a ser tema u objeto -que aparece, es decir, que se coloca en la claridad- es precisamente su reducción al Mismo" (TI, 67). De modo que, según la visión levinasiana, esta tradición habría elaborado todo conocimiento como un acto de apropiación de un objeto por un sujeto, bajo una lógica de dominio y posesión ${ }^{1}$. Como en el idealismo hegeliano, "donde la razón devora al sujeto", también en una u otra medida toda la tradición filosófica "se identifica con la sustitución de las personas por las ideas, del interlocutor por el tema, de la exterioridad de la interpelación por la interioridad de la relación lógica. Los entes remiten al Neutro de la idea, del ser, del concepto" (TI, 110).

Es sabido que Levinas arrebata el trono al ilustre saber de la ontología para concedérselo a la ética. Porque el hombre no estaría, de entrada, en relación con el mundo sino en relación con el otro. De modo que el asombro que daría origen a la filosofía y a todo conocimiento no sería fruto de que el mundo exista, sino de que el otro se halle frente a mí. Es decir, lo que verdaderamente tiene importancia, es originario, es el cara-a-cara, la relación entre los entes singulares, mortales, con rostro. $\mathrm{Y}$ esos seres, esos rostros, no se pueden reducir a "lo Mismo", porque son inconmensurables, inabarcables, Infinitos. Así lo resume el propio Levinas: "Cara a cara: relación ética que no se refiere a ninguna ontología previa. Ella rompe el englobamiento clausurante -totalizante y totalitario- de la mirada teorética. Ella se abre, a modo de responsabilidad, sobre el otro hombre -sobre el inenglobable-: ella va hacia lo infinito" (TI, 9).

Precisamente frente a esa tradición que, desde Sócrates a Heidegger, ha buscado un pensamiento de lo idéntico "sin Otro", frente a los peligros de todo intento 
de Totalidad, Levinas levanta la torre inexpugnable del Infinito del otro. En la proximidad del cara-a-cara, al afrontar otro rostro, algo se despereza en mí, algo despierta. Ese otro me llama de alguna manera, cuestiona mi espontaneidad, la perseverancia en mi "mismidad". Es un extraño que no puedo reducir a una representación, que no puedo absorber sin más, sino que permanece siempre Otro. La necesidad de responderle de algún modo, de salir de mí para ir hacia él, eso es a lo que Levinas llama "ética". Es una relación que supone sentir y no olvidar en ningún momento que el Otro es Infinito, es decir, que no puede quedar subsumido en mi idea de él, y que por tanto toda la labor que yo haga de comprensión, de objetivación y de comparación de ese ser, no lo abarca. Pensar lo contrario, significa caer en los peligros ontológicos de la Totalidad.

¿Significa esto que Levinas reniega de la labor que él mismo hace, es decir, una labor filosófica que necesariamente pasa por el ejercicio de la abstracción, conceptualización, tematización, despersonalización? ¿Significa que rechaza la posibilidad de una racionalidad y de una universalidad que no estuvieran abocados a los pecados de la Totalidad? No. Únicamente antepone la relación concreta del cara-a-cara: porque esa relación sería precisamente la que hace posible no sólo una razón práctica, sino también una razón teórica. Y cualquier desarrollo de cada una de ellas no debería ni olvidar ni subsumir ese origen: "Los interlocutores como singularidades, irreductibles a los conceptos que constituyen al comunicar su mundo y al apelar a la justificación del Otro, presiden la comunicación. La razón supone estas singularidades o estas particularidades, no a título de individuos ofrecidos a la conceptualización o que se despojan de su singularidad para recobrarse idénticas, sino precisamente como interlocutores, seres irremplazables, únicos en género, rostros" (TI, 263).

\section{Rostros que no se "ven", pero se "escuchan"}

¿Qué significa entonces el "rostro" según Levinas"? La "presentación del ente como ente". Pero ¿a quién se le presenta? No a uno mismo. A fin de cuentas, la invención y difusión de espejos o de nítidas superficies reflectantes es un acontecimiento tardío en la historia; en primer lugar, y principalmente, nuestro rostro está expuesto para los otros, es para los otros, como el rostro de los otros es para nosotros. Y bien, en el cara-a-cara, el rostro del otro se nos presenta como una "conmoción", nos despierta moralmente -a nuestro pesar, pues nos incomoda, nos saca de nuestra plácida mismidad-. ¿Cómo ocurre esto?

Ocurre en el ámbito de la "proximidad", cuando se produce un "encuentro ético con un rostro", como lo llama Levinas. Pero ese encuentro implica, de alguna forma, no ver el rostro. Es decir, no atender a quién es su portador, cuáles son sus circunstancias vitales, su edad, su sexo, su raza, su procedencia, su clase social, su apariencia física. No importa su nombre. Ni los trazos biográficos inscritos en el ahondamiento de sus arrugas, en la expresión cuajada por miles de veces repetida. Significa no verlo tampoco como una ventana -más o menos abierta, transparente u opaca- de su psiquismo, de su interior, ni como un compendio de su carácter. Todo ello, todas esas características que forman lo que denominamos la identidad de una persona, todo lo que suele englobarse en la respuesta a la pregunta ¿quién es? o ¿quién eres? de una manera personalizada, y lo que en nuestra interacción cotidiana solemos leer en gran medida en los 
rostros de los demás, en su apariencia o en su forma de expresarse, en definitiva, todo lo que el otro parece, hace o dice no constituiría el significado del rostro del otro, en el sentido ético que le da Levinas.

Todo eso sería como ver los rostros vestidos, los rostros como máscaras, los rostros velados y distorsionados por nuestros anteojos culturales, por nuestros prejuicios y estereotipos. Todos los mecanismos de percepción que normalmente resumimos bajo la noción de visión están conceptualizados, tematizados, son una inmensa máquina de clasificación. Frente a ello, Levinas repite en todas sus obras: el rostro está desnudo, está desnudo, está desnudo. Y precisamente verlo como tal, recibir la llamada, el ruego que procede de esa desnudez, ése es el "lenguaje original del rostro humano despojado de la compostura que le aportan los nombres propios, los títulos y géneros del mundo" (EN, 266).

El rostro es una "epifanía", una "visitación" y, antes que nada, "se expresa" y "significa". Y esa significación "rebasa de entrada las formas plásticas que sin cesar la recubren como una máscara de su presencia en la percepción”. Porque lo que subyace es "la extrema exposición, lo indefenso, la vulnerabilidad misma" (EN, 175). Derrida reconoce en esta "espectralidad", en ese carácter fantasmal del encuentro con el otro, la base misma de una "ética de la hospitalidad y de la acogida" en la que cree que podría reinterpretarse la teoría levinasiana: "Esta ausencia de propiedad determinable, de predicado concreto, de visibilidad empírica, es, sin duda, lo que da al rostro del otro un aura espectral... como si las cualidades, atributos, propiedades «reales» (todo lo que hace que un ser vivo no sea un fantasma) ralentizaran, mediatizaran o comprometiesen la pureza de esa acogida. Es preciso acoger al otro en su alteridad, sin aguardar $\mathrm{y}$, por consiguiente, no detenerse a reconocer sus predicados reales... No hay hospitalidad sin esta apuesta de espectralidad" (Derrida, $1998,141)^{3}$.

Todo esto fue dicho de la manera más clara de la que Levinas era capaz en la entrevista que compone Ética e Infinito: "El acceso al rostro es de entrada ético. Cuando usted ve una nariz, unos ojos, una frente, un mentón, y puede usted describirlos, entonces usted se vuelve hacia el otro como hacia un objeto. ¡La mejor manera de encontrar al otro es la de ni siquiera darse cuenta del color de sus ojos!" (EI, 79). Y continúa: "El rostro es significación, y significación sin contexto. Quiero decir que el otro, en la rectitud de su rostro, no es un personaje en un contexto. Por lo general, somos un «personaje»: se es profesor de la Sorbona, vicepresidente del Consejo de Estado, hijo de Fulano de Tal, todo lo que está en el pasaporte, la manera de vestirse, de presentarse. Y toda significación, en el sentido habitual del término, es relativa a un contexto tal: el sentido de algo depende, en su relación, de otra cosa. Aquí, por el contrario, el rostro es, en él solo, sentido. Tú eres tú. En este sentido, puede decirse que el rostro no es «visto». Es lo que no puede convertirse en un contenido que vuestro pensamiento abarcaría; es lo incontenible, os lleva más allá. En esto es en lo que consiste el que la significación del rostro lo hace salir del ser en tanto que correlativo de un saber. Por el contrario, la visión es búsqueda de una adecuación: es lo que por excelencia absorbe al ser. Pero la relación con el rostro es desde un principio ética. El rostro es lo que no se puede matar, o, al menos, eso cuyo sentido consiste en decir: «No matarás». El asesinato, bien es verdad, es un hecho banal: se puede matar al otro; la exigencia ética no es una necesidad ontológica. La prohibición de matar no convierte al asesinato 
en algo imposible, aun cuando la autoridad de lo prohibido se mantenga en la mala conciencia del mal hecho" (EI, 8081).

\section{Lo que "ordena" el rostro y la posibilidad de la violencia}

Como acabamos de leer, Levinas sostiene que en el encuentro ético con el rostro, éste no se "ve", sino que se "escucha" en forma de orden, y se escucha como una "conmoción de entrañas", como si la orden proviniera, efectivamente, del rostro del otro, pero se oyera en el fondo de uno mismo. Y esa orden dice: "No matarás". Levinas repite siempre ese único imperativo negativo, aunque constantemente lo inviste de contenidos positivos: no es sólo algo que no haya que hacer, sino también algo que hay que hacer, que estoy llamado a hacer. Para empezar, esa orden "puede explicarse más: es el hecho de que no puedo dejar a otro morir solo, de que hay una suerte de apelación a mí" (EN, 130). Exactamente: ese rostro me señala, me llama, me reclama, como si la muerte invisible afrontada por el rostro del otro fuera "asunto mío". Como si estuviese obligado a no dejar al otro en su soledad mortal, como tampoco puedo dejarlo sufrir solo, sin intenta paliar su dolor y reconfortarlo. Porque el sufrimiento o la muerte sólo tienen un "sentido", y se da en lo interhumano: "en la prohibición de ese abandono que se dirige a mí". No es, pues, un sentido intrínseco, sino que viene siempre en acusativo: lo que tiene sentido -el sentido en sí- es la orden que se me dirige para hacerme cargo del otro en esa situación; en otras palabras, mi sufrimiento activo frente al sufrimiento del otro.

Pero la contradicción que subyace al rostro parece, entonces, tremenda: por un lado, es lo que nos prohíbe matar, pero, al mismo tiempo, es lo que está expuesto, amenazado, "como invitándonos a un acto de violencia". "La dura resistencia de esos ojos sin protección" no es suficiente para hacer cumplir esa prohibición moral, como comprobamos día tras día a lo largo y ancho del mundo. ¿Por qué? ¿Cómo explicar esa contradicción?

La resistencia que me opone el otro es precisamente porque es otro, infinito, diferente a mí, no porque me oponga un fuerza hostil. Es, por tanto, la resistencia de un rostro desnudo que, tomado de frente, me ordena esa no indiferencia para con él. Sin embargo, "lo que caracteriza la acción violenta, lo que caracteriza la tiranía, es el hecho de no mirar de frente aquello a lo que la acción se aplica". Es decir, "la violencia es una manera de actuar sobre cualquier ser o cualquier libertad abordándola de lado... La relación con las cosas -el dominio sobre las cosas, esa manera de estar por encima de ellas- consiste, precisamente, en no abordarlas nunca en su individualidad" ( $\mathrm{HOH}, 106)$. La violencia se ejerce, por tanto, después de haber dado un rodeo mediante el que "el no grabado, inscrito sobre la cara por el hecho mismo de ser cara, se convierte en una fuerza hostil o sumisa".

Esos rodeos, esas miradas de lado que impiden sentir la resistencia del rostro desnudo, pueden producirse de muchas maneras. Porque en lugar de percibir el rostro como una singularidad, nos aproximamos a él a partir de una generalidad, a partir de un concepto. Porque lo miramos con los "anteojos" -o mejor, con los "tapones"- del prejuicio, del estereotipo, de la categoría preconcebida. Así que debajo de cada rostro -singular e Infinito- tendemos a ver el rostro verdadero, es decir, el que creemos verdadero y que se ajusta a nuestros prejuicios. Vemos así ese rostro singular al mismo tiempo como una máscara y como una revelación de lo que ya sabe- 
mos que es (judío, musulmán, mujerzuela, etc., cualquier categoría mediante la que cataloguemos de manera denigrante o rebajemos a un nivel inferior al otro). Pertrechados así por el "saber" que "tematiza" los rostros, con esa pantalla protectora ante nuestros ojos/oídos, podemos enfrentarnos al rostro del otro sin sentirnos sacudidos por su vulnerabilidad, por la apelación que esa piel expuesta nos dirige en silencio. Sin tener un "encuentro ético" con él.

Porque ése es el quid de la visión levinasiana: que el bien está al comienzo, en el encuentro cara-a-cara primordial. De modo que la relación ética -nuestro constitutivo ser-para-Otrosería "anterior a la aparición de las libertades, anterior a la guerra que, según Hegel, inaugura la historia". El rostro del otro interpela al yo y lo desembriaga de sí, lo abre a la bondad y al desinterés; es decir, bajo el mandato del rostro, el yo renuncia a su soberanía y se reconstruye de alguna manera como servidor del otro necesitado. Para Levinas el bien precede al mal o, mejor dicho, ambos no están en el mismo plano simétrico: el mal consiste en "la posibilidad de no despertar al otro" y "pertenece al orden del ser en sentido estricto, mientras que, al contrario, el ir hacia el otro es la irrupción de lo humano en el ser, es «de otro modo que ser»" (EN, 140). Derrida lo vuelve a resumir con claridad: "No se puede hacer la guerra sino a un rostro, no se puede matar, ni siquiera prohibir matar, si no es allí donde la epifanía del rostro ha advenido, incluso si se la rechaza, se la olvida o deniega en la alergia" (1998, 118).

\section{Proximidad y asimetría, libertad y responsabilidad}

La violencia se ejerce, por tanto, contra el sentido del rostro. Y ese mismo sentido es lo que da origen, según Levinas, al lenguaje y a la razón: "No es la mediación del signo lo que hace la significación, sino que es la significación (cuyo acontecimiento original es el cara-acara) la que hace posible la función del signo... El sentido es el rostro del otro y todo recurso a la palabra se coloca ya en el interior del cara-a-cara original del lenguaje... La significación es lo infinito, es decir, el Otro" (TI, 220).

El rostro trae así la primera significación, es decir, el surgir mismo de lo racional. Eso sí, puesto que es una razón que se abre al infinito (de los rostros), "el paso a lo racional no es una suspensión de la individualidad precisamente porque es lenguaje, es decir, respuesta al ser que le habla en el rostro y que no tolera más que una respuesta personal, es decir, un acto ético" (TI, 232). Así, el rostro es el que hace posible y donde comienza todo discurso, y es fundamental distinguir entre el Decir y lo Dicho. "El decir es el hecho de que ante el rostro yo no me quedo ahí a contemplarlo sin más: le respondo. El decir es una manera de saludar al otro, pero saludar al otro es ya responder de él. Es difícil callarse en presencia de alguien... Es preciso hablar de algo, de la lluvia y del buen tiempo, poco importa, pero hablar, responderle a él y ya responder de él" (EI, 83). A eso es a lo que se refiere cuando sentencia que "la esencia del discurso es la ética" (TI, 229): no a lo Dicho, sino a esa imposibilidad de la indiferencia, a esa necesidad de Decir al otro. Ese responder a él, responder de él, responsabilizarse de él es, pues, para Levinas, la esencia de la relación moral, e inmediatamente se observa en ello una orden que va mucho más allá del "no matarás" o "no le dejarás morir solo".

Es en la exterioridad, en el otro, donde tiene su eje la moralidad, no en la propia autonomía; no, sin más, en la propia libertad. Levinas retira esa primogenitura 
a la libertad sin más y subraya: la libertad ha de justificarse. Porque reducida a sí misma se lleva a cabo, no en la soberanía, sino en la arbitrariedad. Lejos de Kant, está claro que en Levinas cualquier pensamiento de autonomía es sospechoso de indiferencia hacia la suerte ajena. De modo que la libertad ha de justificarse por la bondad. Ése es el término que utiliza Levinas (especialmente en Totalidad e Infinito) para designar la subjetividad que responde, que se hace responsable del próximo/prójimo. Porque la llamada que proviene del rostro del otro se puede escuchar, responder o no, y ahí reside nuestra libertad. Pero el buen ejercicio de la libertad, es decir, la libertad justificada, es aquél que responde, que acepta esa responsabilidad.

De modo que el otro no constriñe o no limita mi libertad (como lo hace, por ejemplo, para Sartre), sino que lo promueve "al suscitar mi bondad" (TI, 214). Más aún, en la proximidad, al interactuar conmigo el rostro del otro me elige, soy yo el llamado por él y, si acepto esa llamada, ese imperativo de hacerme cargo de él, es entonces cuando me hago libre, cumpliendo con aquello para lo que he sido llamado. El rostro fuerza al sujeto que lo mira a preguntarse: ¿qué le pasará a este otro singular, expuesto y vulnerable, si yo -sujeto singular igualmentedeserto? La responsabilidad es, por tanto, "un principio de individuación" (EN, 134). El mandato que me viene desde el rostro del otro me asigna una responsabilidad para con él y, al hacerlo, me constituye en sujeto moral, singular y libre. Singular porque nadie puede responder por mí. Y libre porque -insistamos en ello- puedo elegir entre abrirme al otro, escuchar su mandato y responder de él en alguna medida, u optar por la ignorancia activa o hasta por la violencia.

Pero, ese otro ¿no escucha también el mismo mandato desde mi rostro? "La recíproca es asunto suyo", corta tajante Levinas. Lo que a mí me incumbe es que yo soy servidor del otro, responsable del otro, sin esperar la recíproca. El origen de la moralidad no es, pues, la igualdad humana, la reciprocidad moral, sino $m i$ responsabilidad hacia el otro. No mis derechos, sino mis deberes para con los otros. Yo como servidor, yo como llamado, impelido a responder a/de los otros, no yo como sujeto paciente de la bondad de los otros. Las relaciones de proximidad son así relaciones totalmente asimétricas.

Pero atención, porque aquí viene el gran salto, tal vez el punto de mayor complejidad del planteamiento levinasiano. Porque el rostro concreto del otro próximo que interactúa conmigo no presenta únicamente el rostro personal que corresponde a tal o cual identidad particular, sino que "tiene la cara del pobre, del extranjero, de la viuda y el huérfano" (TI, 262) ${ }^{4}$. Ésas son las cuatro categorías que, especialmente en Totalidad e infinito, Levinas repite para designar la vulnerabilidad y el abandono que expresa el rostro, pero también para recalcar que en todo rostro se expresan todos los demás rostros, que "el tercero me mira en los ojos del otro", pues "la epifanía del rostro como rostro introduce la humanidad". Es decir, todo rostro es "Todo-Otro: Todo-Otro singular", como condensa C. Moreno (in Barroso/Pérez, 2004, 165).

En definitiva, el rostro del otro suscita al mismo tiempo el problema del tercero, es decir, de la pluralidad de los rostros, y es ahí donde la bondad (ejercida de manera personal, de individuo a individuo, de forma asimétrica y anárquica, en los círculos de la proximidad) ha de abrir paso a la justicia, el espacio de la simetría y los principios universales, el espacio de la abstracción y la despersonalización. 


\section{La sabiduría del amor. De la bondad} a la justicia, y otra vez a la bondad

Y es que Levinas reserva el término "justicia" para designar ese segundo momento de la moralidad, derivado y dependiente del primero, en el que por fin se hace necesario ver los rostros, es decir, reparar en su identidad, compararlos, valorarlos y juzgarlos. Es entonces, ante la presencia del tercero, cuando surge la conciencia, así como la filosofía y el conocimiento en general $\mathrm{y}$, por supuesto, la política o el derecho. Porque si sólo existiera el otro, si cada relación humana fuera dual, yo sólo tendría deberes para con él, estaría llamado a hacerme cargo de él. Pero en su expresión, incluso en su propio rostro, aparece ya el tercero, aparecen todos los otros.

"Yo no vivo en un mundo en donde sólo hay un «cualquier hombre»; en el mundo hay siempre un tercero: también él es mi otro, mi prójimo. Así pues, me preocupa saber cuál de los dos precede al otro. Entonces asistimos al nacimiento de lo teorético, de la preocupación por la justicia, que es el fundamento de lo teorético. Pero la justicia aparece siempre a partir del Rostro, a partir de la responsabilidad respecto de los demás, e implica juicio y comparación, comparación de lo que en principio es incomparable, pues cada ser es único... En cierto momento, es necesaria una balanza, una comparación, un pensamiento y la filosofía sería, en ese sentido, la aparición de una sabiduría que procede del fondo de esa caridad inicial; sería la sabiduría de esa caridad, la sabiduría del amor" (EN, 130).

Los rostros que antes no se veían, no se contextualizaban, ahora han de verse, situarse, compararse, juzgarse. En el encuentro con el rostro, donde yo me convertía en servidor, había un jno juzgues!. Ahora, sin embargo, con la aparición del tercero, de todos los rostros, se impone la orden contraria: ijuzga!. La relación de proximidad -la que propiamente denomina relación ética- era una relación pre-reflexiva y pre-intencional, no suponía conocimiento o comprensión, cálculo o medición. Sin embargo, es ella la que exige después reflexión, conocimiento y verdad. "La relación con el tercero es una corrección incesante de la asimetría de la proximidad en la que el rostro se des-figura. Hay valoración, pensamiento, objetivación... Es así como el prójimo se convierte en visible y, desfigurado, se presenta; es así también como hay justicia para mí. El Decir se fija en Dicho, se escribe, se convierte en libro, derecho y ciencia" (DOM, 238). Exactamente: la justicia es una corrección incesante de la asimetría de la proximidad. Es la construcción de la igualdad, de la equidad, es ahí donde entra el lenguaje de los derechos humanos universales y de todos los constructos jurídico-políticos que amparan y velan por esa equidad. Y es ahí donde yo también soy sujeto de derechos y donde, como ciudadano, estoy sujeto a unas leyes y a unas normas de reciprocidad, a una simetría.

Esa búsqueda de la justicia, la práctica a la que me obliga el ejercicio de la bondad inteligente, pide que sobre la anarquía de la relación original (donde yo soy responsable del otro) se establezca un sistema de orden, unas instituciones y una política. Es decir, todo el armazón del Estado. Pero ello siempre con un infinito cuidado. Porque ni la justicia, ni las leyes, ni la política son el origen o la base de la moralidad, sino una consecuencia y no deben olvidarlo jamás. Recuérdese que "el ser, la totalidad, el Estado, la política, las técnicas o el trabajo están en todo momento a punto de encontrar su centro de gravitación en ellos mismos, de juzgar por su propia cuenta" (DOM, 239), es decir, a punto de 
olvidar a qué han de servir. La ley que hace abstracción de las singularidades es absolutamente necesaria, pero la moralidad, entendida como el despertar a la unicidad vulnerable de cada prójimo, precede a la legalidad y también juzga sus considerandos. Y como es sabido que las normas universales implican frecuentemente ignorar los rostros singulares, es preciso una labor de constante vigilancia. Lo necesario, concluye Levinas, es "un Estado liberal: siempre preocupado por su retraso en la obediencia al rostro del otro" (EN, 251). La justicia no puede estar alejada de las formas de la proximidad, sino que tiene que completarse con ellas: "La justicia no sigue siendo justicia más que en una sociedad en la que no existe distinción entre próximos y lejanos, pero en la que permanece la imposibilidad de pasar de largo al lado del más próximo; donde la igualdad de todos está sostenida por mi desigualdad, por el exceso de mis deberes sobre mis derechos" (DOM, 239). En pocas palabras: la justicia ejercida por las instituciones, debe estar siempre controlada por la relación interpersonal inicial.

Pero, insistamos, esta justicia no está ni al principio ni al final de la moralidad: "En realidad, la justicia no me engloba en el equilibrio de su universalidad, la justicia me conmina a ir más allá de la línea recta de la justicia y nada puede marcar entonces el fin de esta marcha; detrás de la línea recta de la ley, la tierra de la bondad se extiende infinita e inexplorada, al tiempo que necesita todos los recursos de una presencia singular" (TI, 259).

\section{Santidad, una responsabilidad ilimitada}

Como acabamos de leer, "la tierra de la bondad se extiende infinita e inexplorada"; y absolutamente personal, más allá de la impersonal, neutra, universal, contractual y simétrica justicia. Esa justicia, en el fondo, supone una limitación de mi responsabilidad. De mi responsabilidad que es, en la asimetría del cara-acara, ilimitada, como insiste en todo momento Levinas. Es esa inconmensurabilidad de la tarea moral que se le asigna al sujeto, esa insaciabilidad de la exigencia ética lo que más suele llamar la atención en su pensamiento: su apelación a la "santidad".

$Y$ es que el concepto de responsabilidad de Levinas no es el que por lo común manejamos. Porque habitualmente uno es responsable de lo que hace, de las acciones que realiza libremente. Sin embargo, Levinas habla de una responsabilidad no-intencional, anterior a la conciencia y a la elección, "que antecede a todo consentimiento libre, a todo pacto, a todo contrato" (DOM, 150). "Heme aquí, en esta responsabilidad, arrojado en la que nunca ha sido mi culpa, en lo que nunca he hecho, en aquello que no ha estado jamás en mi poder ni en mi libertad, en aquello de lo que no guardo recuerdo". Se trata así de una obediencia que antecede a la comprensión de la orden, de "una urgencia que convierte el imperativo en categórico y en sumisión irreversible" (EN, 181). Levinas gusta de citar la desmedida frase de Dostoievski en Los hermanos Karamazov: «Todos nosotros somos culpables de todo y de todos ante todos, y yo más que los otros». Ese discurso hiperbólico de la responsabilidad culmina en la idea de "sustitución" (o incluso de "expiación”) en De otro modo que ser (1974), donde el sujeto aparece como "rehén del otro" y no puede sentirse inocente ni siquiera del mal que hace el otro.

Todo ello se traduce en una apología de la mala conciencia, en un perpetuo temor por no hacer lo suficiente. 
También en un temor a que "mi lugar bajo el sol" sea la usurpación del lugar de otros. Y puesto que soy responsable, e incluso culpable, más allá de mi voluntad, más allá de mi conocimiento, he de intentar estar en "absoluta vigilancia", tender hacia la "conciencia extrema". En definitiva, ese ejercicio de bondad ilimitada no puede ser más que un ideal de santidad y Levinas no tiene ningún empacho en reconocerlo. Al contrario: "El único valor absoluto es la posibilidad humana de otorgar a otro prioridad sobre uno mismo. No creo que exista una humanidad capaz de recusar este ideal, aunque lo declaremos ideal de santidad. No quiero decir que el hombre sea un santo, digo que es aquel que ha comprendido que la santidad es incontestable. Tal es el comienzo de la filosofía, lo racional, lo inteligible" (EN, 135).

¿Ese horizonte de santidad se entiende únicamente en un contexto religioso? ¿Es la filosofía de Levinas precisamente esa original conjunción entre la tradición filosófica inaugurada por los griegos y la tradición judía? Ciertamente, Levinas utiliza una terminología en gran parte religiosa para hablar del "sentido" de la ética. La llamada del rostro provendría de un "pasado inmemorial", de un "más allá del ser", sería una huella. Y esa huella sería "la proximidad de Dios en el rostro de mi prójimo". Si el rostro del otro me llama, me reclama, me señala, “¿no deberíamos llamar «palabra de Dios» a esta demanda de interpelación, a esta asignación de responsabilidad? ¿No acontece la idea de Dios precisamente en esta asignación más que en la tematización de un objeto pensable, incluso más que en una invitación cualquiera al diálogo?" (EN, 176).

Pero, por mucho que se apoye intensamente en la tradición judía, no es teología lo que hace Levinas. "No elabora ningún discurso sobre Dios, no habla de él, y sin embargo evoca el a-Dios en calidad de corolario indispensable e irrecusable de una reflexión sobre el sentido", como resume Chalier (2002, 196). Y desde luego, no cultiva ninguna doctrina soteriológica, ningún discurso sobre la salvación. No hay ninguna promesa de premio o compensación para esa llamada a la responsabilidad desbordada, a la santidad. Realmente, las interpretaciones ateas del pensamiento de Levinas no parecen ser menos numerosas ni menos sólidas que las religiosas. Si uno trae a la memoria a Tarrou, por ejemplo, el inolvidable personaje de Camus en La peste -aquél preocupado por un "único problema concreto": "cómo llegar a ser santo sin creer en Dios"-, coincidirá en que el humanismo ateo puede estar también, en mayor o menor medida, animado por esa visión de la bondad y la responsabilidad personales más allá de la justicia.

\section{Aporías de la proximidad y la distancia \\ ( $O$ ¿a dónde nos lleva todo esto?)}

Podría discutirse largamente acerca de la consistencia o inconsistencia de este intento de fundamentar la ética que es, al fin y al cabo, lo que hace Levinas. Una fundamentación que no deriva el deber ser del ser, sino que lo sitúa "de otro modo que ser", en un origen pre-ontológico. Un deber ser trascendente, no inmanente al ser y que da su significado y orientación a éste. Querría, sin embargo, dejar a un lado esta cuestión, con el fin de centrarnos ahora en algunas de las posibles derivaciones de la visión levinasiana. En concreto, en aquellas que muestran las aporías y las dificultades inherentes a la proximidad, al encuentro ético cara a cara con el otro (y con todos los otros, en el rostro del otro). 
1. ¿Cómo es posible la violencia? La neutralización de la proximidad ética

Si el bien antecede al mal, es decir, si el ser humano es constitutivamente un serpara-el-otro, si en la proximidad, en el cara-a-cara, se activa esa asimétrica responsabilidad, anterior a todo cálculo y a toda intención, ¿cómo explicar entonces la práctica general de la violencia, del mal ejercido y del mal consentido contra otros seres humanos? ¿Explica suficientemente Levinas por qué el no matarás gritado silenciosamente por el rostro del otro no impide que se le mate? ¿Explica suficientemente el cómo? ¿Explica suficientemente el por qué?

Levinas expone, ya lo hemos visto, que para desoir la orden que proviene del rostro del otro hay que olvidar u ocultar el ser infinito del otro, absorbiéndolo de alguna manera en lo Mismo mediante una generalización o una abstracción de su singularidad, de su unicidad. No mirando el rostro de frente, sino mediante un "rodeo" que convierte ese rostro en una "fuerza hostil o sumisa". Pero serán otros pensadores los que, tirando de este hilo, planteen una explicación más contundente. Es el caso de Alain Finkielkraut (1993), quien lleva a sus últimas consecuencias lo que Levinas parece querer decir. Recuérdese que para éste la moral no es algo que sale de mí -espontáneamente, voluntariamente- hacia el otro, sino al revés: es algo extraño a mí -el rostro del otro hombre- el que me obliga a romper mi indiferencia, el que me molesta y me impone una responsabilidad para con él. De modo que la preocupación por los demás sobreviene en mí a pesar de mí mismo, como efecto de un traumatismo. Y el yo no puede sustraerse de ese deber, "sin conservar la huella de su deserción", insiste Levinas.

Finkielkraut encuentra en ello el origen mismo de ciertos actos de violencia.
Estos provendrían de "la violencia con que el otro me desaloja, me persigue y hostiga hasta los rincones más recónditos de mí mismo. De ahí la agresividad que puedo sentir por ese personaje indiscreto..., por ese indeseable: el prójimo". Ello quiere decir que "el amor al prójimo explica el odio pues es anterior" (1993, 107). El mal ejercido o el mal consentido procederían por tanto, en primer término, de una voluntad de castigar al otro por su intrusión en mi existencia: "Antes que ser intolerancia a la diversidad, el odio al otro hombre (del cual el antisemitismo suministra el modelo) manifiesta la intolerancia del yo frente a su propia responsabilidad", insiste Finkielkraut (1993, 121). Violencia sin límites contra el otro como una huida, como un modo de ponerse a cubierto de su demanda moral, tan irremediable como intransferible.

El sociólogo Zygmunt Bauman también recurre a Levinas (desde Modernidad y Holocausto, 1987, pero más sistemáticamente en Ética posmoderna, 1993) para explicar ese "impulso de escapar" del peso de la libertad y de la responsabilidad, de la carga moral que supone el tener que responder a la llamada que proviene de esa "pobreza esencial" del rostro. De hecho, el descubrimiento de Levinas ("que se me reveló como un pensamiento final, como una culminación", según confiesa, 2001b, 78) le llevó a replantear toda la perspectiva sociológica. Bauman acepta sin discusión el punto de partida ofrecido por aquél: "La responsabilidad moral -ser para el Otro antes que estar con el Otroes la primera realidad del ser, un punto de partida más que un producto de la sociedad. Antecede a cualquier compromiso con el Otro, ya sea por medio del conocimiento, la evaluación, el sufrimiento o la acción" $(1993,21)^{5}$. Pero, si eso es así, habría que revisar la visión canónica, durkheimiana, de la moralidad 
como producto de la sociedad, como el logro de un control social reforzado por sanciones. Es decir, si esa relación de responsabilidad moral es previa a la institucionalización y a la normativización de la sociedad, habría que aceptar que "lo que hacen las sociedades es manipular la moralidad más que producirla" (2002, 79).

Bauman llama generalmente "impulso moral" -lo que Levinas no hace- a esa responsabilidad asimétrica que se despierta en el yo en el "encuentro ético" con el otro. Pues bien, cualquier organización social consistiría entonces en neutralizar el efecto disruptivo del impulso moral y en canalizarlo hacia una dirección conveniente. Esos mecanismos sociales acotarían la responsabilidad moral del sujeto, de modo que se activara sólo hacia algunos rostros, mientras que el resto de individuos quedarían abstraídos, difuminados, des-rostrados. Bauman distingue tres mecanismos principales (1993, 144): 1) asegurar que haya distancia, en vez de proximidad entre los dos polos de acción: el de hacer y el de sufrir, de modo que quienes reciben la acción queden fuera del alcance del impulso moral de los actores; ello se hace, por ejemplo, mediante la especialización y la parcelación del trabajo, a fin de que los agentes difícilmente aprecien su propia tarea, tan pequeña e insignificante, como moralmente relevante; en consecuencia, la responsabilidad flotada de los hechos no puede asignársele a nadie en particular; 2) exceptuar a algunos "otros" de la categoría de seres humanos iguales a nosotros, es decir, deshumanizarlos: borrar su rostro; 3) fragmentar a las personas en diferentes partes o funciones, de modo que las acciones se dirijan a características específicas de esas personas, desviando o evitando una vez más el encuentro de frente.
Todos esos mecanismos que neutralizan o "anestesian" la proximidad moral donde despierta la responsabilidad para el otro habrían sido especialmente promovidos en las sociedades modernas -arguye Bauman- por medio de la tecnología, el mercado, el Estado y la estetización del espacio social. El predominio de la razón instrumental, la juridización, etc., habrían contribuido así a crear distancia ética $\mathrm{y}$, por tanto, a hacer menos audible la llamada de los rostros y más fácil ejercer la indiferencia o la agresividad para con algunos otros.

2. La ambivalencia de la razón: el saber del Infinito frente al saber de la Totalidad

Para Bauman, "la ética posmoderna es la de Levinas" (1993, 98). Para sostener esta afirmación, parte en primer lugar de una concepción de la ética moderna a la que luego contrapondrá la expuesta por Levinas. Pues bien, la ética moderna sería el intento de regulación del estarcon-los-otros mediante normas codificables. Frente a ello, la concepción del serpara-los-otros mostraría que "la moralidad es la condición de anomia perpetua e irreparable": "Podemos legislar deberes a partir de reglas universales, pero la responsabilidad moral sólo existe y puede realizarse a título individual" (1993, 65). La ética posmoderna aceptaría esta visión de que la incertidumbre debe acompañar forzosamente la condición del yo moral, de manera que no cabría ninguna codificación, formalización o universalización ética; tendería, por tanto, lejos de todo código, a "repersonalizar" la moralidad. En definitiva, la ética se reduciría a ese "impulso moral" no racional -insiste Bauman-, señalado por Levinas.

Pero la responsabilidad moral de la que habla Levinas ¿es no racional o, 
simplemente, pre-racional? Creo que con lo expuesto hasta ahora puede defenderse perfectamente lo segundo. Porque, para mostrar a Levinas como epítome de la "ética posmoderna", Bauman ha tenido que olvidar o apartar (no los menciona siquiera) dos puntos fundamentales de la teoría de aquél. Por un lado, la filosofía -es decir, la racionalidad filosóficaentendida como "sabiduría del amor", a la que obligaría la inquietud por la justicia, originada por la presencia del tercero, por la pluralidad de los rostros; del otro lado, la insistencia levinasiana de que ese tercero -todo-otro-singular- aparece ya en el mismo rostro del otro. Ambos planteamientos, estrechamente relacionados, tienen difícil encaje en la ética posmoderna que presenta Bauman en 1993 (aunque después la haya modificado en parte, 1997, 2001ab).

No es que Levinas elabore ninguna teoría de la racionalidad, pero sí deja claro que es constitutivamente ambigua. Esto es, que corre constantemente el peligro de ejercerse como la tiranía de lo impersonal, del principio universal que no atiende al infinito de los rostros desnudos. Como el sujeto moral kantiano que va hacia el otro a partir de una forma -la de la ley universal-, sin dejar que el rostro de las personas le perturbe su autonomía. Recordemos que la violencia se ejerce cuando se abordan los rostros de soslayo y que la forma principal de llevar a cabo y, sobre todo, de legitimar esa violencia, ha sido mediante la construcción del saber de la totalidad, el saber erigido para aprehender, controlar $\mathrm{y}$ dominar.

Pero con esa crítica Levinas no pretende ir en contra de la racionalidad, de la filosofía o de la universalidad. Al contrario, éstas son imprescindibles precisamente para responder de la mejor manera posible a la llamada del rostro, para hacer justicia. Sólo recuerda cuál es el sentido de todo ello, la orientación originaria de esa montaña de conceptos, abstracciones y retóricas. Así pues, aunque no lo diga explícitamente, distingue el saber que trabaja -consciente o inconscientemente- para la Totalidad (y que por ello coquetea siempre con algún tipo de totalitarismo), del saber que no olvida que su tarea es proteger, cuidar, responder al Infinito que se expresa en el rostro de los otros. Un saber impulsado por la búsqueda de la justicia, es decir, por la bondad juiciosa, preocupado siempre porque llega demasiado tarde, o insuficientemente, a la llamada del rostro del otro.

¿Acaso no es más explicativa esta teoría de la ambivalencia de la racionalidad que la que insiste en ofrecer necesariamente un sesgo moral positivo al mero hecho de pensar? Como, por ejemplo, cuando a raíz del juicio a Eichmann, Hannah Arendt se plantea si la irreflexión, la ausencia del hábito de pensar y de juzgar puede ser el motivo que impulsa a hacer el mal, de esa manera banal como ejerció el oficial nazi. Pueden encontrarse numerosas razones para argüir la conexión entre una cosa y otra, pero no parece que ello explique todas las formas de ejercer el mal, de adherirse a él o de permanecer indiferente. ¿Acaso alguien podría sugerir irreflexión o ausencia de pensamiento en el caso de Heidegger, por ejemplo? La aplastante sentencia de Gadamer ("Heidegger fue el más grande de los pensadores y el más pequeño de los hombres") no hace sino ilustrar lo que la experiencia cotidiana nos enseña: que alguien puede ser muy culto, muy instruido, incluso un fino pensador $\mathrm{y}$, sin embargo, egocéntrico, malévolo, cruel. O, simplemente, que su saber puede estar dirigido, como en el caso de Heidegger, a construir o a legitimar algún modo de Totalidad.

George Steiner suele contar que ha consagrado toda su vida a la pregunta: 
“¿Cómo se puede tocar a Schubert por la noche, leer a Rilke por la mañana y torturar al mediodía?" Es decir, a preguntarse por qué la cultura no ofreció un verdadero obstáculo a la barbarie. O, aún más, por qué "a veces llegó a alentarlo". Entender que los conocimientos, que las aproximaciones cognitivas o estéticas pueden ser también vehículo de despersonalización, de distancia ética, de sordera, que desvirtúan el sentido del saber tal como lo plantea Levinas, creo que puede ayudar a responder a tan acuciantes preguntas.

\section{La fraternidad como fuente de libertad e igualdad}

La verdadera sabiduría estaría ligada, entonces, a la transición de la bondad - pureza del vínculo ético, dual, singular y singularizante, asimétrico- a la justicia -simetría de una comunidad de iguales, de ciudadanos con derechos, potencialmente universal-. Porque es en esa transición (que en realidad no es una transición en el tiempo, pues ambas "conmociones" serían coetáneas), ante la presencia del tercero, cuando surge la necesidad de la verdad, la necesidad de saber. "Tener conciencia es saber; para hacer justicia es preciso saber: objetivar, comparar, juzgar, formar conceptos, generalizar, etc. Ante la multiplicidad humana se imponen estas operaciones, en las que la responsabilidad respecto de los demás -que es caridad y amor- se extravía 6 y, por ello, busca una verdad" (EN, 252). Buscar la justicia sería, repite Levinas, "comparar los incomparables". Y es que no habría que olvidar que en realidad los seres humanos son incomparables, es decir, únicos, infinitos, inabarcables en una Totalidad.

Pero ¿cómo proceder a esta comparación de los incomparables, a esa necesaria labor de tematización y despersonalización, "sin alienar los rostros"? ¿Cómo tomar la distancia necesaria, sin traicionar la llamada de la proximidad? Ésa es la gran preocupación de Levinas. En el orden de la justicia, los seres no se comparan como rostros sino como ciudadanos; como miembros de un género, no como "únicos". Pero constantemente ronda el peligro de que la necesaria construcción de ese aparato de cálculo, de negociación, se convierta en un sistema autónomo que olvide completamente su origen, su para qué. El peligro de que lo Dicho se consolide, se haga autosuficiente, busque la unidad, borre la responsabilidad ilimitada que justifica esta preocupación por la justicia. A cada instante, pues, inclusive en el momento de la comparación, la fuente viva de la moral ha de seguir siendo la singularidad. Y es que, como subraya Chalier, "Levinas insiste en que la singularidad única e irreemplazable de las personas no tiene ninguna oportunidad de que se la tenga en cuenta -en moral tanto como en política-, si no se empieza por ella y si no se vuelve a ella. Ello no significa faltar a la universalidad de lo humano, sino ir hacia ella, cada día más, movido por la preocupación por las singularidades" $(2002,104)$.

En la proximidad -en la projimidadel otro se me presenta precisamente como Otro, como "diferencia que es no-indiferencia", como hermano, pero no como un alter ego (es decir, como alguien que pudiera subsumir en lo Mismo): "Todos los otros que me obsesionan en el otro no me afectan ni como «ejemplares» del mismo género reunidos con mi prójimo por semejanza o por comunidad de naturaleza; ni como si fuesen individuaciones del género humano o fragmentos del mismo bloque... Los otros me conciernen de golpe. Aquí la fraternidad precede a la comunidad de género" (DOM, 239). Es decir, me conciernen antes de saber que hay 
una comunidad de género o algún tipo de identificación común. Eso que Levinas llama fraternidad es, pues, previo a cualquier construcción igualitaria o, mejor dicho, es lo que ordena esa construcción igualitaria.

Por eso, si bien Levinas no elabora ninguna teoría de la justicia, sí insiste en recordar su origen y su finalidad, proporcionando así algunos criterios para juzgar a los que desarrollan esa labor teórica. Normalmente, la justicia -igual que la política o el derecho- suele entenderse como la regulación del estar-con-losotros. Tomemos por ejemplo a Habermas. Su teoría se basa en la libertad y la igualdad de los interlocutores. No obstante, permanece más bien ciega para el tercer gran valor ilustrado, para la fraternidad o la solidaridad (esencialmente asimétrica). Porque los sujetos de la comunidad ética habermasiana son unos otros abstractos, virtuales, no reales; es decir, ni son vulnerables ni están necesitados de solidaridad. Levinas, en cambio, muestra que sólo a partir de la fraternidad -a partir del ser-para-losotros- puede fundarse, pensarse y ejercerse sin excesos tanto la libertad como la igualdad.

¿Es ello una seria objeción al planteamiento comunicativo de la ética realizado por Habermas? No lo creo. Es más, Levinas aplaudiría sin duda el paso de una racionalidad monológica a una dialógica, una racionalidad siempre atenta a lo que significa el Decir, frente a los peligros de una consagración de lo Dicho que prescinda por tanto de la pluralidad -e inabarcabilidad- de los interlocutores. Sin embargo, podríamos afirmar, con Pedro Rojas (2000, 55), que el planteamiento de Habermas "obtiene toda su legitimidad y sentido sólo una vez que la tarea de fundamentación ha bajado un escalón más, y ha descubierto, por ejemplo, junto a Levinas, bajo la ponderación de las razones que sostiene a la justicia, la insobornabilidad de una relación ética asimétrica más antigua que todo cálculo, que todo consenso y que todo diálogo".

\section{La proximidad: la distancia al acecho}

Esa relación ética asimétrica, que pondera un hacerse cargo del otro ilimitado, más acá y más allá de la libertad y la igualdad protegidas por la justicia, ¿cómo puede concretarse? ¿Cómo se traduce tamaña responsabilidad? Lo único que Levinas contesta a esto es que no importa "que se sepa o no cómo asumirla, que se pueda o no hacer algo concreto por el otro. Decir: heme aquí. Hacer algo por otro. Dar" (EI, 91). A veces no se puede hacer nada excepto arrostrar impotentemente el sufrimiento o la muerte del otro, pero aun así se le puede responder "heme aquí". ¿Puede traducirse entonces esa responsabilidad como compasión? Sí, responde Levinas, pero no se reduce en absoluto a ello: "el sufrimiento de la compasión, el sufrir porque otro sufre, no es más que un momento de una relación mucho más compleja -y también más completa- de responsabilidad respecto del otro" (EN, 133)7.

En la relación dual, en el ámbito de la "pequeña bondad" (como la llamaba Vassilij Grossman) de persona a persona, ¿cómo se responde al imperativo de la proximidad? Por muy urgente y apremiante que sea el mandato de un rostro singular, para responsabilizarse correctamente $¿$ no hace falta por lo general una distancia? ¿O sea, una representación de la situación, una contextualización, una visualización, un cálculo de las consecuencias? Se necesita calibrar, enjuiciar, evaluar la forma concreta en la que podemos responsabilizarnos. Se requiere una distancia no para corregir la asimetría de 
la proximidad -como en el caso de la justicia-, sino precisamente para cumplirla adecuadamente.

He ahí la fundamental aporía de la proximidad. Si bien recibo el llamamiento que me dirige el rostro desnudo del otro de una manera pre-intencional y pre-reflexiva, a la hora de concretar la respuesta-llevado precisamente por esa preocupación por el prójimo- deberé ser juicioso para no causar un mal mayor del mal que quiero evitar o del bien que quiero hacer. Tendré que imaginarme las distintas vías de acción, deliberar y decidir qué es lo mejor en ese caso concreto. Todo ello implica que el otro será por un momento convertido en una idea mía, re-presentado, puesto en un terreno donde ya mandan la intención y el cálculo. De hecho, ponerme en la piel del otro sería interpretado por Levinas como poner al otro en mi piel, es decir, como alguna forma de subsumir al Otro en lo Mismo, con todos los riesgos que ello acarrea de terminar convirtiendo la buena voluntad en alguna forma de opresión.

Pero no parece que haya escapatoria: para cumplir con el mandato de la proximidad - desde la forma de la "pequeña bondad" a la de la "gran justicia"- ha de mediar alguna forma de distancia -pensamiento, intención, cálculo; generalización, abstracción, tematización-. El peligro, es evidente, consiste en instalarse en ese alejamiento, en habitar en él, sin despertar al Infinito singular de los rostros. Es decir, en olvidar el origen y el sentido de esa toma de distancia. En dormitar en lo Dicho, borrando el significado del Decir.

Tal vez pueda verse todo esto como una reformulación de la condición trágica del hombre. Y también, como el reto de una sabiduría práctica que trabaja para el ejercicio y la difusión de la bondad inteligente.

\section{BIBLIOGRAFÍA}

LEVINAS, Emmanuel (Obras citadas)

(1961), Totalidad e Infinito (TI), Salamanca, Sígueme, 1999.

(1972), Humanismo del otro hombre (HOH), Madrid, Caparrós, 1998.

(1974), De otro modo que ser o más allá de la esencia (DOM), Salamanca, Sígueme, 2003.

(1982), Ética e Infinito (EI), Madrid, Visor, 1991.

(1987), Fuera del sujeto (FS), Madrid, Caparrós, 2002.

(1991), Entre nosotros. Ensayos para pensar en otro (EN), Valencia, PreTextos, 2001.

Arteta, A., La compasión. Apología de una virtud bajo sospecha, Barcelona, Paidós, 1996.

Barroso Ramos, M. / Pérez Chico, D. (eds.), Un libro de huellas. Aproximaciones al pensamiento de E. Levinas, Madrid, Trotta, 2004.

BAUMAN, Z., Ética posmoderna (2003), Buenos Aires, Siglo XXI, 2004.

-, La posmodernidad y sus descontentos (1997), Madrid, Akal, 2001.

—, La sociedad individualizada (2001a), Madrid, Cátedra, 2001.

BAumAn, Z. / TESTER, K., La ambivalencia de la modernidad y otras conversaciones (2001b), Paidós, 2002.

Bello Reguera, G., La construcción ética del otro, Oviedo, Nobel, 1997.

Chalier, C., Por una moral más allá del saber. Kant y Levinas, Madrid, Caparrós, 2002.

Courtine-Denamy, S., Le visage en question. De l'image à l'èthique, Paris, Eds. de la Difference, 2004.

Derrida, J., Adiós a E. Levinas. Palabra de acogida, Madrid, Trotta, 1998.

FinkielkraUt, A., La sabiduría del amor, Gedisa, 1993. 
GonzÁlez R. Arnáiz, G., E. Levinas: humanismo y ética, Madrid, Cincel, 1992.

Greisch, J./ Rolland, J. (eds.), Emmanuel Lévinas. L'éthique comme philosophie première, Paris, Ed. du Cerf, 1994.

Peñalver, P., Argumento de alteridad. La hipérbole metafísica de
E. Levinas, Madrid, Caparrós, 2001.

RoJAs, P., "La ética del lenguaje: Habermas y Levinas". Revista de Filosofía, $\mathrm{n}^{\mathrm{o}}$ 23, Univ. Complutense, Madrid, 1998.

SuCASAS, A., El rostro y el texto: la unidad de la ética y la hermenéutica, Anthropos , 2001.

\section{NOTAS}

1 Gabriel Bello resume muy bien esta cuestión (in Barroso/Pérez, 2004, 86): "El efecto final es que el objeto pasa a formar parte de las propiedades (cognitivas) del sujeto: ideas, sensaciones, conocimientos, contenidos de conciencia, etc. El principio de apropiación (y dominio) es el que rige el conocimiento del ser u ontología, y el conocimiento o autoconocimiento del yo, del otro y de las relaciones entre ambos. La ontología en tanto que «fundamento», así como todo lo fundado en y por ella (la lógica, la epistemología, la antropología, la ética y la política), nacen ya marcadas por el principio de apropiación y dominio". Bello presenta, así, la división entre una ética "del individualismo posesivo", por un lado, basada en ese principio de apropiación, posesión y dominio, y de la que derivarían nuestra centralidad ética en la autonomía y la forma de presentar y fundar los derechos humanos, y, por otro lado, en una ética de la alteridad, la responsabilidad y la hospitalidad, que seguiría a Levinas y estaría basada en un principio del don y de la no-apropiación.

2 El "rostro" no es necesariamente la cara, aunque sí preferentemente. Levinas aclara que "todo el cuerpo, una mano, la curva de un hombro, puede expresar tanto como el rostro" (TI, 272). También, por qué no, una nuca: Grossmann cuenta en Vida y Destino que "en la Loubianka, en Moscú, la gente guardaba cola ante el famoso postigo mediante el que se podían enviar cartas o paquetes a los parientes o amigos detenidos por «delitos políticos» $\mathrm{u}$ obtener noticias de ellos, leyendo cada uno en la nuca de quien le precedía los sentimientos y las esperanzas de su miseria". Así, en una nuca también se podría leer "toda la debilidad, toda la mortalidad, la mortalidad desnuda y desarmada del otro", como en un rostro (EN, 280).

3 Ese rostro al mismo tiempo concreto y abstracto, espectral, también ha sido estupendamente analizado por César Moreno (in Barroso/Pérez,
2004): "Levinas ha situado la pregunta por el Otro ante un extraño páramo en el que al Otro como Rostro no se le podría reducir a Mundo, ni a Cuerpo, ni a Psiquismo, ni a Imagen ni a Signo" (152). "Rescatar al Otro como Rostro de toda significación mundana, de lo que el Otro «es-enel-mundo», o de lo que «parece» o de lo que lo hace «comprensible» o conceptualizable, o incluso que lo arropa": ésa sería la experiencia ética fundacional. "No se trata de que, propiamente, en un sentido objetivo, el Rostro sea sin-mundo... sino de que el tomarlo en el Mundo no nos dará su significación ética, y que el Mundo, al inmiscuirse en esa significación, acabaría por tergiversarla, ocultándonosla" (158).

4 Pero, al mismo tiempo, el otro tiene la cara, "a la vez, del señor llamado a investir y a justificar mi libertad". Y ello porque el otro se sitúa simultáneamente en "una dimensión de altura y de abatimiento" (TI, 100). Aunque Levinas insista más en el aspecto de "abandono" o de "pobreza esencial" del rostro, no por ello deja de subrayar que ese mismo rostro me llama desde una altura, como un señor al que yo, incluso a pesar de mí mismo, hubiera de servirle. Se trata de una puntualización importante porque, como subraya Aurelio Arteta en su estudio sobre la compasión, ésta tiene necesariamente un doble asiento: la dignidad del hombre, no menos que la finitud y la vulnerabilidad humanas. Porque "sin esa dignidad previa que le atribuimos, tampoco habría qué compadecer en él", porque "el hombre es mísero precisamente por gozar de semejante valor, y tanto más miserable cuanto mayor distancia manifieste su vida (singular y colectiva, material y espiritual) con respecto a aquella dignidad" (1996, 147). Precisamente, Arteta se ha centrado en esa doble dimensión humana de "altura" y "abatimiento", en sus esclarecedores ensayos sobre, respectivamente, la virtud de la admiración (2002) y de la compasión (1996). 
5 Que la moralidad se dé antes que la ontología le parece precisamente lo decisivo: "La ética busca en el 'antes' del ser no porque espere que los tan anhelados fundamentos se escondan ahí, sino porque sabe que es precisamente el acto de buscar ahí lo que fundamenta al ser moral, ya que es, por así decirlo, el único fundamento que la moralidad podría tener" $(1993,89)$.

6 Se "extravía" dice Levinas, y Derrida va más allá al interpretar este extravío como un primer "perjurio": "si el cara-a-cara con lo único compromete la ética infinita de mi responsabilidad para con el otro en una especie de juramento por adelantado, de respeto o de fidelidad incondicional, entonces el surgimiento ineluctable del tercero, y con él de la justicia, rubrica un primer perjurio. Silencioso, pasivo, doloroso pero indefectible, un perjurio semejante no es accidental o secundario, es tan originario como la experiencia del rostro. La justicia comenzaría con ese perjurio... El derecho comenzaría con un perjurio así, traicionaría la rectitud ética" (1998, 52).

${ }^{7}$ De hecho, como hemos comprobado, Levinas llama en numerosas ocasiones "amor, caridad" a esa responsabilidad para con el otro. Aún así, si se desgrana mínimamente en qué consiste ese hacerse cargo del prójimo, ¿no puede defenderse que es el sentimiento compasivo el primero y fundamental en esa asignación asimétrica, el que está en la base de todo lo demás? Arteta, en su estudio sobre la compasión, arguye que como mera emoción, ésta puede ser pasajera, selectiva, parcial, pasiva. Sin embargo, como virtud, como el correcto y reflexivo ejercicio de ese sentimiento, la compasión es universal, permanente, activa. De modo que, a su juicio, "la compasión comparece como el límite, el umbral, el punto cero de las virtudes de la humanidad. Por debajo de ella, estamos en lo inhumano". Pero es también "la última virtud. Viene al final de todas ellas, porque ninguna es suficiente para lo que el ser humano demanda" (1996, 275). Y concluye con estas sentencias que recuerdan a Levinas: "Cabría decir que la compasión es una forma primera e intuitiva de justicia". "Por anhelar una justicia inalcanzable, este grado de compasión será siempre una justicia insatisfecha, y toda justicia real, a su vez, una compasión imperfecta". "De modo que, satisfechas las exigencias del derecho, a la piedad le resta todavía un campo infinito para su ejercicio" (1996, 288). La diferencia estriba, por tanto, en que Arteta considera como virtud -es decir, como algo que debe aprenderse y ejercitarse como un acto voluntario y reflexivo- lo que Levinas expone como originario o pre-originario. 